\title{
Consumer involvement in dietary guideline development: opinions from European stakeholders
}

\author{
Kerry A Brown ${ }^{1, *}$, Maria Hermoso ${ }^{2}$, Lada Timotijevic ${ }^{1}$, Julie Barnett ${ }^{3}$, Inger Therese L \\ Lillegaard $^{4}+$, Irena Řehư̌rková ${ }^{5}$, Ainhoa Larrañaga ${ }^{6}$, Azra Lončarević-Srmić $^{7}$, \\ Lene Frost Andersen ${ }^{4}$, Jiří Ruprich ${ }^{5}$, Laura Fernández-Celemín ${ }^{6}$ and Monique M Raats ${ }^{1}$ \\ ${ }^{1}$ Food Consumer Behaviour and Health Research Centre, Department of Psychology, Faculty of Arts and Human \\ Sciences, University of Surrey, Guildford, Surrey, GU2 7XH, UK: ${ }^{2}$ Division of Metabolic and Nutritional \\ Medicine, Dr von Hauner Children's Hospital, Ludwig-Maximilians-University of Munich Medical Centre, Munich, \\ Germany: ${ }^{3}$ Department of Information Systems and Skills, Brunel University, Uxbridge, UK: ${ }^{4}$ Department of \\ Institute of Basic Medical Sciences, University of Oslo, Oslo, Norway: ${ }^{5}$ The National Institute of Public Health in \\ Prague, Centre for Health, Nutrition and Food, Brno, Czech Republic: ${ }^{6}$ European Food Information Council, \\ Brussels, Belgium: ${ }^{7}$ Cardiac Risk in the Young (CRY), Tadworth, UK
}

Submitted 7 July 2012: Final revision received 11 October 2012: Accepted 16 October 2012: First published online 27 November 2012

\begin{abstract}
Objective: The involvement of consumers in the development of dietary guidelines has been promoted by national and international bodies. Yet, few best practice guidelines have been established to assist with such involvement.

Design: Qualitative semi-structured interviews explored stakeholders' beliefs about consumer involvement in dietary guideline development.

Setting: Interviews were conducted in six European countries: the Czech Republic, Germany, Norway, Serbia, Spain and the UK.

Subjects: Seventy-seven stakeholders were interviewed. Stakeholders were grouped as government, scientific advisory body, professional and academic, industry or non-government organisations. Response rate ranged from $45 \%$ to $95 \%$.

Results: Thematic analysis was conducted with the assistance of NVivo qualitative software. Analysis identified two main themes: (i) type of consumer involvement and (ii) pros and cons of consumer involvement. Direct consumer involvement (e.g. consumer organisations) in the decision-making process was discussed as a facilitator to guideline communication towards the end of the process. Indirect consumer involvement (e.g. consumer research data) was considered at both the beginning and the end of the process. Cons to consumer involvement included the effect of vested interests on objectivity; consumer disinterest; and complications in terms of time, finance and technical understanding. Pros related to increased credibility and trust in the process.

Conclusions: Stakeholders acknowledged benefits to consumer involvement during the development of dietary guidelines, but remained unclear on the advantage of direct contributions to the scientific content of guidelines. In the absence of established best practice, clarity on the type and reasons for consumer involvement would benefit all actors.
\end{abstract}

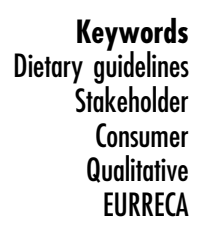

A variety of national and international bodies have promoted the involvement of consumers as stakeholders in health research, policy and practice ${ }^{(1-3)}$. This has included the development of dietary guidelines ${ }^{(4)}$, a set of statements that could be expressed in both nutrient- and food-based terms for the promotion of nutritional well-being in the general public ${ }^{(5)}$. Suggested benefits of consumer involvement have related to the process of scientific decision

$\uparrow$ Current address: Norwegian Scientific Committee for Food Safety, PO Box 4044 Nydalen, N-0404 Oslo, Norway. making, such as fostering trust in the process via transparency, as well as improving the quality of final decisions ${ }^{(4,6,7)}$.

In terms of process, consumer involvement has been led by a move for greater accessibility to science ${ }^{(6,8,9)}$, where "people have the right and duty to participate individually and collectively in the planning and implementation of their health care, ${ }^{,(10)}$. Regarding content, consumer involvement is premised upon incorporation of consumer values and perspectives to broaden the range of knowledge considered and allow the opportunity for assumptions to be challenged ${ }^{(4,6,11-13)}$. 
Consumer involvement can take a variety of forms in terms of who would be involved, in what way and to what degree ${ }^{(13)}$. The general public is the intended enduser of dietary guidelines. Thus, all members of the public have the potential to be involved, from individual lay consumers to those representing vulnerable consumers or consumers in general, such as consumer groups or consumer advocates ${ }^{(14)}$. Participation may be via the use of qualitative or quantitative consumer research data (e.g. focus groups testing draft guidelines or food choice and dietary intake data) or at invitational/open consultations and decision-making meetings ${ }^{(6)}$.

There has been limited research in Europe on the current practice of consumer involvement in the development of dietary guidelines ${ }^{(15)}$. Timotijevic et $a l .{ }^{(9)}$ explored stakeholder (including consumer groups) involvement in the decision-making process for micronutrient recommendations and suggested involvement differed across European countries, influenced by a country's political and historical context. For example, in the Czech Republic, where new democratic nutrition policies were in their infancy, stakeholder involvement was encouraged but not consistently employed. In the UK, stakeholder involvement was more formalised. This has likely been in response to the visible health scares that occurred in the UK (e.g. variant/non-variant CJD, the human prion disease caused by BSE), as well as the positioning of public health nutrition in key policy decisions $^{(9)}$.

Inconsistency in the employment of consumer involvement across Europe may also be due, in part, to the lack of evidence-based best practice for consumer involvement in scientific decision-making processes ${ }^{(16)}$. Minimal data have been available to evaluate the impact of consumer involvement or highlight the potential advantages of involvement in the development of dietary guidelines ${ }^{(9)}$.

A greater degree of research has been conducted in relation to consumer involvement in the clinical healthcare field ('clinical' referring to the treatment of disease, predominantly at an individual level, as opposed to dietary guidelines which refer to public health promotion at a population level). Various models to describe consumer involvement have been developed, such as Arnstein's ladder of participation ${ }^{(17)}$, which contained three main categories of involvement: non-participation, degrees of tokenism and degrees of citizen power. However, this has since been criticised for its lack of applicability in today's health-care context ${ }^{(18)}$. More recent research has suggested three general classifications of involvement: public communication (e.g. recipients of information campaigns), public consultation (e.g. responders to draft consultation documents) and public participation (e.g. members of advisory committees). Yet, research in the health-care field has also been limited by a paucity of data evaluating the impact of various types of consumer involvement ${ }^{(6,13,19-21)}$. This was illustrated by an updated Cochrane review which emphasised the lack of data from randomised controlled trials on the effects of consumer involvement in health-care decisions, such as the development of clinical practice guidelines $^{(22)}$. Alternative study designs have attempted to evaluate the impact of consumer involvement, particularly regarding public engagement in health policy development ${ }^{(23,24)}$. However, evaluation has been hampered by the methodological difficulties of identifying and measuring positive/negative impacts of consumer involvement on either the decision-making process (e.g. decision-maker experience, engagement, financial or time costs) or the content and effectiveness of final decisions and their implementation (e.g. content quality, improvements in public health, use of guidelines) $)^{(6,25)}$.

The international and European political will for consumer involvement in scientific decision-making processes does not appear to have been transferred into the practice of consumer involvement across Europe. This may be explained by country-specific social, historical or political contexts. However, implementation may have been further complicated by the lack of established best practice guidelines or evidence on the most effective form of consumer involvement. The current study used a qualitative interview design and sought to explore any commonalities in the beliefs of a variety of stakeholders from different European countries on consumer involvement in the development of dietary guidelines. The aim was to bring a multi-national and multi-stakeholder perspective to discussions on potential avenues for pan-European consumer involvement best practice guidelines.

\section{Method}

\section{Design}

Qualitative semi-structured interviews explored stakeholders' beliefs about consumer involvement in dietary guideline development (both nutrient- and food-based recommendations). A common protocol was used by the researchers responsible for data collection in each country. Interviews were held face-to-face or over the telephone. Consent was obtained for participation and all interview recordings, which were later transcribed verbatim. All quotes have been made anonymous.

\section{Setting}

Interviews were conducted during 2008-2009 in six European countries: the Czech Republic (CZ), Germany (GE; predominantly Germany, but also D-A-CH countries' recommendation representatives), Norway (NO; predominantly Norway, but also one Nordic nutrition recommendation representative from Denmark), Serbia (SE), Spain (ES) and the United Kingdom (UK). The countries sampled represented diversity in geographical location, socio-cultural and institutional infrastructure as well as history of dietary guideline development. 
Table 1 Stakeholder interview sample

\begin{tabular}{lrrrrrrr}
\hline & \multicolumn{7}{c}{ Stakeholder group } \\
\cline { 2 - 8 } Country & IND & GOV & NGO & PRO & SAB & Other & Total \\
\hline CZ & 4 & 4 & 4 & 6 & 2 & 1 & 21 \\
GE & 2 & 2 & 2 & 2 & 2 & 0 & 10 \\
NO & 2 & 2 & 1 & 1 & 3 & 0 & 9 \\
SE & 3 & 3 & 4 & 5 & 0 & 0 & 15 \\
ES & 1 & 3 & 2 & 4 & 2 & 0 & 12 \\
UK & 4 & 1 & 2 & 1 & 2 & 0 & 10 \\
Total & 15 & 15 & 15 & 19 & 12 & 1 & 77 \\
\hline
\end{tabular}

IND, food industry; GOV, government; NGO, non-governmental organisation; PRO, professional/academic; SAB, scientific advisory body; CZ, Czech Republic; GE, Germany + D-A-CH countries' recommendation representatives; NO, Norway + one Danish Nordic nutrition recommendation representative; SE, Serbia; ES, Spain; UK, United Kingdom.

\section{Participants}

Participants were recruited based upon a template of stakeholders involved in the development of (micro) nutrient recommendations in each country. Stakeholders were defined as individuals or organisations willing to invest resources and accept some responsibility for the development of (micro) nutrient recommendations - may also be consumers'. They were grouped as government, scientific advisory body (SAB), professional and academic, industry or non-government organisations (NGO; included charities, consumer and special interest groups, Table 1). The twenty-one $\mathrm{CZ}$ participants were recruited within the context of a workshop. Remaining participants were recruited by email or telephone. The response rates ranged from $45 \%(\mathrm{GE})$ to $95 \%(\mathrm{CZ})$.

\section{Interview schedule}

The semi-structured interview schedule consisted of three sections:

1. Stakeholder general beliefs about dietary guidelines.

2. Stakeholder beliefs on consumer awareness, understanding and use of dietary guidelines.

3. Stakeholder beliefs on consumer involvement in developing dietary guidelines.

The current study presents results from the research question related to section 3: stakeholder beliefs on consumer involvement in developing dietary guidelines. Nevertheless, data from all three sections of the interview were explored regarding this research question.

The term 'dietary guideline' was believed to be the most understandable and translatable term across stakeholders and countries and was initially used in section 1 of the interview schedule. Previously published results from this data set reported variation in the interviewee-led interpretation of the term 'dietary guideline ${ }^{,(26)}$. Thus, the reader should be aware that 'dietary guideline' has referred to both nutrient- and food-based recommendations throughout the present paper.

Prompts were used where necessary to encourage elaboration on relevant points. All interview schedules were translated by the researchers responsible for data collection, with care taken to maintain the meaning of each question.

\section{Data analysis}

The data were analysed using thematic analysis ${ }^{(27)}$. The aim of thematic analysis is to describe how thematic contents are elaborated by groups of participants and to identify meanings that are valid across many participants $^{\text {,(28) }}$. A skeleton coding structure was created and modified by researchers in each country during preliminary analyses. The final template used by all six countries allowed the addition and omission of codes where necessary. All countries completed coding in their own language and then created a summary of identified themes and illustrative quotes in English. Qualitative data analysis software NVivo 8, 2008 assisted the collation and thematic analysis of multiple-country data.

\section{Results}

The two main themes, (i) type of consumer involvement and (ii) pros and cons of consumer involvement, together with their related sub-themes, are reported below with illustrative quotes presented in Tables 2 and 3.

\section{Type of consumer involvement}

\section{1a. Direct or indirect involvement}

Stakeholders appeared to discuss several ways that consumers could be involved in dietary guideline development, which have been categorised as either indirect or direct involvement. Indirect consumer involvement utilised information on consumers to aid the decision making during dietary guideline development (e.g. firsthand anecdotal practice experience or consumer research data on consumer health indicators, dietary intake/ nutrient status, lifestyle attitudes/behaviours or opinions on dietary guideline communication materials). Direct involvement referred to lay consumers, consumer group representatives or consumer advocates actively participating in the decision-making process (e.g. presence on committee meeting panels or via plenary/workshop/ written consultation practices).

\section{1b. Which consumers to involve?}

Stakeholders were not always clear who they believed would be the most suitable consumers to involve. In relation to direct consumer involvement, the majority of interviewees often referred to 'consumer organisations', 'consumer associations' and 'consumer groups', with only a few interviewees considering direct lay consumer involvement. The difficulty in identifying the appropriate consumer organisations to involve was highlighted by a few of the stakeholders in terms of the large number of organisations that could potentially represent consumers. 
Table 2 Main theme 1: type of consumer involvement

\begin{tabular}{|c|c|}
\hline Sub-theme & Quote (identification reference, country, stakeholder group) \\
\hline $\begin{array}{l}\text { 1a. Direct or indirect } \\
\text { involvement }\end{array}$ & $\begin{array}{l}\text { 'It would have to be a multidisciplinary body and within that body should be one of the consumer } \\
\text { representatives' ( } 41, \mathrm{SE}, \mathrm{GOV}) \\
\text { 'I think consumers already participate through the surveys done with them, as the FFQ or the diet histories' } \\
(56, \mathrm{ES}, \mathrm{NGO})\end{array}$ \\
\hline $\begin{array}{l}\text { 1b. Which consumers } \\
\text { to involve? }\end{array}$ & $\begin{array}{l}\text { 'They've just got a list of consumer organisations, and actually it's a much broader sector than that. So say for } \\
\text { example they tend not to think of environmental organisations as being consumer organisations' (68, UK, NGO) } \\
\text { 'Predominantly the relatively educated consumer [will be more aware of dietary guidelines] because he will } \\
\text { also understand them right away' (22, GE, GOV) }\end{array}$ \\
\hline $\begin{array}{l}\text { 1c. Timing of } \\
\text { involvement }\end{array}$ & $\begin{array}{l}\text { '... [the consumers] can of course not be a part of what the dietary guidelines should be, but how one should } \\
\text { give such advice and guidelines' ( } 32, \mathrm{NO}, \mathrm{NGO}) \\
\text { 'Perhaps at the first stages, someone representing the consumers, i.e. a Consumer Association, should } \\
\text { participate to guide and give their opinion. At a final stage, when the draft is done, then we could test it with } \\
\text { the consumers' (57, ES, IND) }\end{array}$ \\
\hline
\end{tabular}

SE, Serbia; GOV, government; ES, Spain; NGO, non-governmental organisation; UK, United Kingdom; GE, Germany + D-A-CH countries' recommendation representatives; NO, Norway + one Danish Nordic nutrition recommendation representative; IND, food industry.

Table 3 Main theme 2: pros and cons of consumer involvement

\begin{tabular}{ll}
\hline Sub-theme & Quote (identification reference, country, stakeholder group) \\
\hline 2a. Interests & 'What do not belong to the process, in my opinion, are for example interest associations [...] it could \\
compromise the objectivity' (23, GE, PRO) \\
'We sometimes deal with consumers' questions about foods in our consumers' association. But they are more \\
connected to food safety and quality. So DG aren't very important for us. Consumers don't approach us with \\
these questions' (1, CZ, NGO) \\
'But I do not see that the consumers have a large role in the development of the DG. That is scientific based, \\
but it is extremely important that the consumers have trust in the process of making the DG' (33, NO, SAB) \\
'[ ...] part of their [consumer representatives] responsibility is to ensure that we are operating in a way that is \\
2bcessible. All of the processes that we engage in are open for public scrutiny, and there are explicit \\
invitations at the start of many of the process for people to provide information' (69, UK, GOV) \\
'We can still learn from consumers, their wishes and their habits, good and bad' (42, SE, PRO) \\
'I don't think there are any disadvantages other than, it might take longer, because obviously a bigger group, \\
you're going to have more discussion. You're going to have, you know, more views to take into account' \\
(70, UK, PRO) \\
'The disadvantage is that consumers complicate scientists' work [...]' (2, CZ, SAB)
\end{tabular}

GE, Germany + D-A-CH countries' recommendation representatives; PRO, professional/academic; DG, dietary guidelines; CZ, Czech Republic; NGO, non-governmental organisation; NO, Norway + one Danish Nordic nutrition recommendation representative; SAB, scientific advisory body; UK, United Kingdom; GOV, government; SE, Serbia.

Regarding indirect consumer involvement, consumers were described at both a broad population level and a subgroup level. Dietary guidelines were considered applicable to the 'general population' with terms such as 'citizens' or the 'general public' frequently used whilst discussing the data required for guideline development, as well as ensuring effective communication and use of the guidelines. Yet, stakeholders rarely identified themselves as consumers (aside from one stakeholder - UK $\mathrm{SAB}$ ). Consumer data specific to various target subgroup populations were also mentioned. Subgroups appeared to represent those vulnerable to nutrition inadequacy or overexposure defined by both physiological and social descriptors (e.g. life stage, sex, age as well as education level, socio-economic status, rural/urban, health motivation).

\section{1c. Timing of consumer involvement}

The majority of stakeholders appeared to believe that consumer involvement, either direct or indirect, was necessary at the end of the dietary guideline development process mainly in regard to guideline communication. A number of interviewees also advocated some benefit in consumer involvement at the initial stages of dietary guideline development. There was a sense that consumer information or opinion would not be required during what was regarded as the scientific content stage of development in between the initial scoping of the problem and later communication stages.

\section{Pros and cons of consumer involvement}

\section{2a. Interests}

Several interviewees commented that direct consumer involvement in the decision-making processes may detract from the - scientific or other - objectivity of the decision-making process. There was some concern that consumer representatives may act as lobbyists or that ideological or political motives could influence what was regarded as a scientific and independently objective decision-making process. In contrast, a small number of interviewees believed that food safety might be a higher 
priority for consumers rather than nutrition issues such as dietary guideline development. For example, one stakeholder (CZ NGO) commented on the resources of the consumer organisations. They stated that the often limited resources (manpower and finance) of small consumer organisations would be likely to prioritise food safety above nutrition matters such as dietary guidelines, whereas other stakeholders such as the food retail industry might have the capacity to fund involvement in both areas.

\section{2b. Credibility and trust}

The majority of stakeholders recognised that consumer trust in the process of dietary guideline development was an advantage to ensure that the guidelines were perceived as credible. However, only a minority identified direct consumer involvement as a route to establish trust and legitimise the process through adequate representation and transparency. The majority advocated the use of consumer indirect involvement via consumer research, particularly in relation to testing communication messages. The identification of consumers' health and dietary status, lifestyle habits, values and motivations were considered important during the development of guidelines and 'testing' the dietary guidelines. Such consumer research was expected to improve guideline implementation and effectiveness. Only one stakeholder suggested that direct consumer representation during the decision-making process might improve the content of the guidelines by bringing a degree of practicality to the discussions (UK NGO).

\section{2c. Complications}

Several interviewees mentioned that direct consumer involvement would be a disadvantage to the process due to increasing the time and financial cost of guideline development. It was perceived that consumers who did not have any prior knowledge in the dietary guideline area would find it difficult to follow discussions in terms of the technical language used and interpretation of the data, which would limit the degree of their involvement and lengthen discussions.

\section{Discussion}

Research findings provided an insight into the beliefs of multiple stakeholders across a variety of European countries on the implementation of consumer involvement in the development of dietary guidelines. Stakeholders appeared aware of several different types and potential pros and cons of consumer involvement. Benefits were primarily in relation to indirect involvement via the use of consumer research data to inform guideline development and communication strategies. In addition, direct involvement was believed to help foster trust and credibility in the guideline process to assist with effective guideline implementation. Regarding guideline content, stakeholders either minimally or negatively referred to direct consumer involvement, citing the development of content to be a predominantly scientific stage of the process.

The role of consumer involvement as described above may be explained by the stakeholders' perception of who a 'consumer' was. In the identified theme 'type of consumer involvement', there was a grouping of consumers by education level and a disassociation with consumers by all but one stakeholder. Stakeholders may have perceived an 'imagined consumer' ${ }^{(29)}$, wherein consumers were viewed as passive beneficiaries of expert advice rather than active contributors to advice formation (e.g. public communication involvement ${ }^{(21)}$ ). Thus, consumer involvement was considered more appropriate in the non-scientific aspects of guideline development. Similarly, in the identified theme 'pros and cons of consumer involvement' there was a perception that consumers would lack the expertise necessary to follow the technical content during scientific discussions. Stakeholders identified this as a limiting factor for consumer involvement which may also prolong and increase the financial costs of the guideline development process.

Lack of expertise and resultant additional financial and time burdens has been cited in previous research as a disadvantage to consumer involvement during scientific decision making and guideline development ${ }^{(9,20)}$. Consumer involvement, particularly during technical discussions, may present a number of difficulties ${ }^{(30)}$. In contrast, consumers may not lack expertise and it may take no longer or be more expensive to involve consumers. Regardless, if difficulties are present they can be overcome to allow consumer views to either complement the technical knowledge of non-consumer experts or challenge any previously held assumptions, both of which may improve the quality of guideline content and ultimate success of any guideline implementation ${ }^{(14,31)}$.

The potential effect of consumer involvement on scientific objectivity was also mentioned as a further barrier to consumer involvement during the guideline content discussions. Stakeholders referred to the possible effect of consumer ideological or political vested interests which might bias the scientific decision-making process during guideline development. Previous research has recognised the difficulties of establishing a truly objective scientific process and that bias has the potential to influence a process such as the development of guidelines ${ }^{(32)}$. Nevertheless, this is relevant to all parties involved in the process, as there is a possibility of inherent bias via personal, professional, academic or commercial interests $^{(14,32)}$. Many scientific bodies have routinely requested members to disclose potential conflicts of interest ${ }^{(33,34)}$. Difficulties remain with the responsibility on the individual to identify what might constitute a potential conflict of interest. Yet, the transparent declaration of interest from all stakeholders, including consumers, as well as the 
explicit detailing of evidence and values underpinning decisions, may help to negate some of the apprehension shown towards consumer involvement in the present study. Indeed, increased transparency and greater involvement of consumers has been suggested as a means to limit conflict of interest issues and prevent bias from individual or group private interests which may not be in line with public health ${ }^{(35)}$.

Stakeholders did acknowledge the benefits of consumer involvement in terms of providing an increased sense of legitimacy, credibility and trust in the process of developing guidelines. The need for legitimacy, credibility and trust was particularly discussed in relation to countries which had multiple guidelines or a high degree of media influence that was seen to confuse or dilute a consistent dietary guideline public health message. This has often been proposed as a primary purpose for consumer involvement or public engagement with science $^{(12,36-38)}$. In addition, arguably, in the Western world at least, trust in the food system and those who oversee its delivery and advice has become ever more important in relation to nutrition where a number of consumers have become far removed from the origin of their food ${ }^{(39)}$.

There may be limits to the degree these findings can be transferred outside the sample studied. The exploratory nature of the present study justified the use of a qualitative design and steps were taken to limit any biased interpretation of these perceptions. A common protocol was employed to maximise study rigour via clarity of the research goal and the consistent method of data collection, analysis and reporting. This also enabled the combination of data across countries. To maintain the cultural context and authenticity of the data the majority of qualitative interpretation was conducted in the native language. It was not possible to conduct data analysis by country or stakeholder group due to the incompatible nature of the stakeholder groups, who appeared to vary in their involvement of dietary guideline development across countries. Instead data were analysed with a focus on commonalities across the whole data set and any observed individual differences were highlighted.

The stakeholder views depicted were not intended to represent the totality of views from the six countries or those involved in setting either (micro) nutrient-based or food-based dietary guidelines. Interviewees varied in their previous experiences as either the consumers or working alongside consumers, involved during the development of dietary guidelines. It is unclear the degree these past negative or positive experiences of consumer involvement may have influenced any assumptions about consumers and consumer involvement reported in the study. In addition, the confusion surrounding the terminology in this area ${ }^{(26,40)}$ has led to the present study interviewing those responsible for and collecting results referring to a variety of nutrient- and food-based guidelines (Dietary Reference Values, nutrient goals, Food-Based Dietary Guidelines).
Nevertheless, the views presented have provided a glimpse of how consumer involvement may be perceived in relation to the development of 'dietary guidelines' from a wide range of stakeholders across multiple countries. Results have suggested that political advocacy for consumer involvement in scientific decision-making needs to be accompanied by clarification on the role of any consumer involvement from the outset of any collaboration. Identifying the purpose, advantages and/or disadvantages of this involvement may assist with identifying the type of involvement required (e.g. public communication, public consultation or public participation ${ }^{(21,23)}$ ) and ensuring that expectations are clear, the significance of any input is considered $^{(13,22,41)}$ and the possibility of token consumer involvement ${ }^{(17)}$ or the misuse of often limited (guideline development or consumer) resources is avoided.

Future research may yet establish evidence-based best practice for the most effective type of consumer involvement to support the successful development of dietary guidelines. Alternatively, it may not be possible to establish harmonised best practice. Different degrees or types of consumer involvement may be warranted due to the variance in experience, influence and visibility of consumers across different countries or situations. Until such time that further data become available on the impact of different forms of consumer involvement, it may be prudent to support a flexible approach based upon the practical experience of others and a general set of agreed principles, such as the agreement of clear and specific aims, objectives and outcomes ${ }^{(3,22,31,42,43)}$

\section{Conclusions}

Organisations will continue to call for greater consumer involvement, primarily as part of a wider request for improved public engagement with science and a multistakeholder approach to preventing dietary-related ill-health. There is currently limited data on the impact of, or to justify best practice for, consumer involvement in the development of dietary guidelines. Until this can be established it may be wise to adopt a flexible approach to involving consumers. The main conclusion from the present study has been that whatever type of consumer involvement is undertaken it would be advisable to make transparent the role of consumers to all parties prior to any involvement, as well as in the final report writings, to aid the evaluation of consumer impact.

\section{Acknowledgements}

Sources of funding: The work reported herein was carried out within the EURRECA Network of Excellence (http://www.eurreca.org), financially supported by the Commission of the European Communities, Specific Research Technology and Development (RTD) Programme 
'Quality of Life and Management of Living Resources' within the Sixth Framework Programme, contract no. 036196. This does not necessarily reflect the Commission's views or its future policy in this area. Ethics: Ethical approval was not required. Conflicts of interest: No conflicts of interest have been declared by authors. Authors' contributions: K.A.B., L.T., J.B. and M.M.R. were responsible for the study concept and design. K.A.B., M.H., L.T., I.T.L.L., I.R., A.L., A.L.-S., L.F.A., J.R. and L.F.-C. conducted data collection, analysis and the composition of individual country summary reports. K.A.B. coordinated data collection and analysed data across countries. K.A.B. drafted and wrote the manuscript. K.A.B., M.H., L.T. and J.B. edited the manuscript. All authors were involved in manuscript revisions. Acknowledgements: The authors would like to acknowledge the contributions made to data collection by Mirjana Gurinovic, Romana Novakovic and Jasna Tepsic at the Institute for Medical Research, Department of Nutrition and Metabolism, University of Belgrade, Serbia.

\section{References}

1. European Commission (2002) Science and Society Action Plan. Brussels: European Commission.

2. Hanley B, Bradburn J, Barnes M et al. (2004) Involving the Public in NHS, Public Health and Social Care Research: Briefing Notes for Researchers, 2nd ed. Eastleigh: INVOLVE Support Unit; available at http://www.twocanassociates.co. uk/perch/resources/files/Briefing\%20Note\%20Final_dat(2).pdf

3. Horey D (2010) Consumer Involvement in the Cochrane Collaboration: Background Paper. Auckland: Cochrane Collaboration.

4. European Food Safety Authority, Panel on Dietetic Products, Nutrition, and Allergies (2010) Scientific Opinion on principles for deriving and applying Dietary Reference Values. EFSA J 8, 1458.

5. World Health Organization (1996) Preparation and Use of Food-Based Dietary Guidelines: Report of a Joint FAO/WHO Consultation. Geneva: WHO.

6. Entwistle VA, Renfrew MJ, Yearley S et al. (1998) Lay perspectives: advantages for health research. BMJ 316, $463-466$.

7. Saunders C \& Girgis A (2010) Status, challenges and facilitators of consumer involvement in Australian health and medical research. Health Res Policy Syst 8, 34.

8. European Commission (2000) Science, Society and Citizens in Europe. Brussels: Commission of the European Communities.

9. Timotijevic L, Raats MM, Barnett J et al. (2010) From micronutrient recommendations to policy: consumer and stakeholder involvement. Eur J Clin Nutr 64, Suppl. 2, S31-S37.

10. World Health Organization (1978) Declaration of Alma-Ata. Geneva: WHO.

11. European Commission (2001) European Governance: A White Paper. COM (2001) 428 Final. Brussels: Commission of the European Communities.

12. Irwin A \& Michael M (2003) Science, Social Theory and Public Knowledge. Milton Keynes: Open University Press.

13. Boote J, Telford R \& Cooper C (2002) Consumer involvement in health research: a review and research agenda. Health Policy 61, 213-236.

14. Williamson C $(1998)$ The rise of doctor-patient working groups. BMJ 317, 1374-1377.
15. Baggott R \& Forster R (2008) Health consumer and patients' organizations in Europe: towards a comparative analysis. Health Expect 11, 85-94.

16. Telford R, Beverley C, Cooper C et al. (2002) Consumer involvement in health research: fact or fiction? $\mathrm{Br} \mathrm{J} \mathrm{Clin}$ Govern 7, 92-103.

17. Arnstein SR (1969) A ladder of citizen participation. J Am Inst Plann 35, 216-224.

18. Tritter JQ \& McCallum A (2006) The snakes and ladders of user involvement: moving beyond Arnstein. Health Policy 76, 156-168.

19. Hanley B, Truesdale A, King A et al. (2001) Involving consumers in designing, conducting, and interpreting randomised controlled trials: questionnaire survey. BMJ 322, 519-523.

20. Oliver S, Clarke-Jones L, Rees R et al. (2004) Involving consumers in research and development agenda setting for the NHS: developing an evidence-based approach. Health Technol Assess 8, issue 15, 1-148.

21. Rowe G \& Frewer LJ (2005) A typology of public engagement mechanisms. Sci Technol Hum Values 30, 251-290.

22. Nilsen E, Myrhaug H, Johansen M et al. (2006) Methods of consumer involvement in the development of healthcare policy and research, clinical practice guidelines and patient information material. Cochrane Database Syst Rev issue 3, CD004563.

23. Rowe G, Rawsthorne D, Scarpello T et al. (2010) Public engagement in research funding: a study of public capabilities and engagement methodology. Public Underst Sci 19, 225-239.

24. Walls J, Rowe G \& Frewer L (2011) Stakeholder engagement in food risk management: evaluation of an iterated workshop approach. Public Underst Sci 20, 241-260.

25. Brown KA, Timotijevic L, Barnett J et al. (2011) A review of consumer awareness, understanding and use of foodbased dietary guidelines. Br J Nutr 106, 15-26.

26. Brown KA, Timotijevic L, Barnett J et al. (2011) Micronutrient recommendation stakeholders' beliefs on dietary guidelines: a qualitative study across six European countries/regions. Eur J Clin Nutr 65, 872-874.

27. Boyatzis RE (1998) Transforming Qualitative Information: Thematic Analysis and Code Development. Thousand Oaks, CA: SAGE Publications.

28. Joffe H \& Yardley L (2004) Content and thematic analysis. In Research Methods for Clinical and Health Psychology, pp. 56-68 [D Marks and L Yardley, editors]. London: SAGE Publications.

29. Maranta A, Guggenheim M, Gisler P et al. (2003) The reality of experts and the imagined lay person. Acta Sociol 46, 150-165.

30. Crawford MJ, Rutter D, Manley C et al. (2002) Systematic review of involving patients in the planning and development of health care. BMJ 325, 1263-1265.

31. Schunemann HJ, Fretheim A \& Oxman AD (2006) Improving the use of research evidence in guideline development: 10. Integrating values and consumer involvement. Health Res Policy Syst $\mathbf{4}, 22$.

32. Norris SL, Holmer HK, Burda BU et al. (2012) Conflict of interest policies for organizations producing a large number of clinical practice guidelines. PLoS One 7, e37413.

33. Government Office for Science (2011) Code of Practice for Scientific Advisory Committees (CoPSAC 2011). London: Government Office for Science.

34. Schütz T, Herbst B \& Koller M (2006) Methodology for the development of the ESPEN guidelines on enteral nutrition. Clin Nutr 25, 203-209.

35. Harris RP, Helfand M, Woolf SH et al. (2001) Current methods of the US Preventive Services Task Force: a review of the process. Am J Prev Med 20, 21-35.

36. House of Lords Select Committee on Science and Technology (2000) Science and Society (Third Report). London: HMSO. 
37. Vale CL, Thompson LC, Murphy C et al. (2012) Involvement of consumers in studies run by the Medical Research Council (MRC) clinical trials unit: results of a survey. Trials 13, 9.

38. Coveney J (2008) Food and trust in Australia: building a picture. Public Health Nutr 11, 237-245.

39. Fischler C (1988) Food, self and identity. Soc Sci Inform $\mathbf{2 7}$, 275-292.

40. Doets EL, de Wit LS, Dhonukshe-Rutten RAM et al. (2008) Current micronutrient recommendations in Europe: towards understanding their differences and similarities. Eur J Nutr $\mathbf{4 7}$, $17-40$.

41. Fudge N, Wolfe CDA \& McKevitt C (2008) Assessing the promise of user involvement in health service development: ethnographic study. BMJ 336, 313-317.

42. Kelson M (2005) The NICE patient involvement unit. Evid Based Healthcare Public Health 9, 304-307.

43. Telford R, Boote JD \& Cooper CL (2004) What does it mean to involve consumers successfully in NHS research? A consensus study. Health Expect 7, 209-220. 